\title{
Association of Aldosterone and Cortisol with Cardiovascular Risk Factors in Prehypertension Stage
}

\author{
Sadiqa Badar Syed ${ }^{1}$ and Masood Anwar Qureshi ${ }^{2}$ \\ ${ }^{1}$ Department of Physiology, Medical and Dental College, Bahria University, Karachi 75260, Pakistan \\ ${ }^{2}$ Department of Physiology, Dow University of Health Sciences, Karachi 74200, Pakistan
}

Correspondence should be addressed to Sadiqa Badar Syed, sadiqasyed@yahoo.com

Received 3 February 2012; Revised 18 June 2012; Accepted 2 July 2012

Academic Editor: Samy I. McFarlane

Copyright ( 2012 S. B. Syed and M. A. Qureshi. This is an open access article distributed under the Creative Commons Attribution License, which permits unrestricted use, distribution, and reproduction in any medium, provided the original work is properly cited.

\begin{abstract}
Background. The Pakistani population has higher incidence of cardiovascular (CV) diseases at younger ages, due to undiagnosed, uncontrolled hypertension (HTN). A variety of associated HTN stressors is also reported. The study plans to understand the variables associated with initiation of HTN in this population. Objective. To find plasma aldosterone and cortisol relationship with some CV risk factors (obesity, dyslipidemia, hyperglycemia, sodium and potassium) in different stages of HTN particularly prehypertension. Subjects and Methods. The study conducted on 276 subjects (25-60 years), classified into prehypertensive $(n=55)$, HTN stage- $1(n=70)$ and II $(n=76)$ according to 7 th JNC report and compared with normotensive controls $(n=75)$. The anthropometric profiles (height, weight, waist circumference, Body Mass index) and BP recorded. Serum cortisol, aldosterone, total cholesterol, Low density lipoproteins, blood glucose, $\mathrm{Na}^{+}$and $\mathrm{K}^{+}$, using standard laboratory techniques, were determined in fasting blood samples. Results. Subjects were mostly overweight and obese (80\%, 90\%, and 76\% in pre-HTN, stage-I and II versus $69 \%$ in controls). The aldosterone level (ng/dl) was in higher normal range (9.17-12.41) and significantly correlated to BMI (0.587) in controls, and to TC (0.726) and LDL $(0.620)$ in pre-HTN stage-I. The cortisol level was positively correlated $(P<0.01)$ to BMI (0.538), $\mathrm{Na}^{+}(0.690)$ and $\mathrm{K}^{+}(0.578)$ in control, and to BMI (0.628) and WC (0.679) in pre-HTN group, showing its association with BMI > 25. Conclusion. Pre-HTN stage among Pakistani population with successive increase in various risk factors of HTN in relation to aldosterone and cortisol has been identified. Interaction of the risk factors with endogenous levels of these hormones may initiate stages of HTN.
\end{abstract}

\section{Introduction}

Hypertension (HTN) is a major risk factor for target organ damage leading to many major diseases such as myocardial infarction, stroke, impaired renal function, and ultimately renal failure. Prevalence of HTN varies in different parts of the world, affecting $28 \%$ of adult population in North America, $40 \%$ in European countries, 25\% in Far East region, 15\% in South Asian countries, and 26\% in Eastern Mediterranean region [1]. The prevalence and severity varies markedly with age and was expected to raise from 972 million people in the year 2000 to 1.54 billion individuals in 2020. In Pakistan, HTN is regarded as the second commonest deadly disease as there are 12.5 million diagnosed cases of HTN and 12,000 die every year because of complications of this disease. The Pakistan Medical Research Council data published in 1998 revealed that $18 \%$ of Pakistani population is hypertensive, but it seems to have much increased since that time, as the prevalence is now lout of every 3 middle aged persons [2].

Despite its high prevalence, identification of its key determinants remains challenging due to its multifactorial and polygenic nature. The genetic, environmental, and dietary factors possibly mediating via hormonal, metabolic, and neurological changes in tissues and organs are manifested as phenotypes [3]; however, the precise mechanism of its occurrence and progression remains obscure. Identification and awareness about prehypertension (pre-HTN) stage with high normal blood pressure (BP) was stressed by 7 th JNC report to avoid its progression into established HTN [4]. 
Genetic studies on Mendelian HTN have provided better understanding of etiological mechanisms including synthesis and degradation of mineralocorticoids and their receptors, renal sodium channels reabsorption mechanisms, regulation of kidney specific sodium-chloride cotransporters, and regulation of renin angiotensin aldosterone system. Thus, information about effects of adrenal hormones aldosterone and cortisol on myocardium, vascular endothelium and HTN is being accumulated [5]. Aldosterone is a mineralocorticoid (MC) hormone, having $30-50 \%$ of its total plasma concentration in free form [6]. Cortisol, the glucocorticoid (GC) hormone, on the other hand, has 100-fold higher free levels in circulation than aldosterone with high intrinsic MC activity, though its action is blunted, at the level of kidney, by local conversion to cortisone [7]. Under normal physiological condition, cortisol does not contribute much to MC action in typical target tissues, for example, kidney, but can lead to HTN when this conversion is blunted by deficiency or inhibition of the enzyme 11-beta hydroxysteroid (HSD2) [8]. There is possibility of common sequences of amino acids shared between GC and MC receptors that allow cortisol to bind with the same high affinity as aldosterone binds to MC receptor [9].

The plasma aldosterone secretion is stimulated by either a rise in serum potassium $\left(\mathrm{K}^{+}\right)$or a fall in serum sodium $\left(\mathrm{Na}^{+}\right)$concentration. It exerts its effect initially by increasing epithelial $\mathrm{Na}^{+}$channel $\left(\mathrm{ENa}^{+} \mathrm{C}\right)$ activity via an aldosterone specific enzyme eventually resulting in increased $\mathrm{Na}^{+}$and decreased $\mathrm{K}^{+}$levels [10]. The phenomenon of aldosterone escape in which the body maintains aldosterone production through mechanisms not involving angiotehsin-II has also been suggested to cause HTN, followed by events like promotion of $\mathrm{Na}^{+}$and water retention, accumulation of extracellular fluid volume, and increased cardiac output. This results in achievement of a steady state with renal $\mathrm{K}^{+}$wasting and increase in arterial BP [11]. Aldosterone also activates $\mathrm{MC}$ receptor in vascular smooth muscle, thus decreasing arterial compliance and increasing peripheral resistance [12]. The primary aldosteronism, previously thought to be present only in $1 \%$ of individuals with HTN, is now suggested to be present in up to $15 \%-20 \%$ of unselected individuals with HTN [13].

Human adipocytes in overweight and obese individuals have been documented to secrete potent $\mathrm{MC}$ releasing factor that simulates adrenal aldosterone production, in addition to expressing a complete renin angiotensin system [14]. Angiotensin-II stimulation of aldosterone release is mediated by AT-1 receptors, that in turn is associated with insulin resistance (IR), resulting in several metabolic changes such as hyperglycemia, dyslipidemia, and HTN by accelerating the atherosclerotic process and endothelial dysfunction [15].

Several mechanisms are suggested for body fat mass influence on secretion of aldosterone and cortisol [16]. These include direct effect of cortisol by increasing hepatic production of angiotensinogen, by binding $\mathrm{MC}$ receptor, and increasing vascular reactivity. The elevated levels of free fatty acids activate a neuroendocrine reflex, leading to increased circulating levels of cortisol [17] known to be associated with many dysfunctions including HTN [18].
The prevalence of HTN in Pakistan is one of the highest in the world and it is regarded as a high cardiovascular risk population due to increased incidences of stroke, myocardial infarctions, and end stage kidney disease at younger ages $(<45$ years) [19]. The purpose of this study was to determine the association of aldosterone and cortisol with anthropometric measures like body mass index and waist circumference and metabolic factors such as fasting blood glucose, total cholesterol, low density lipoproteins, and electrolytes like sodium and potassium in different stages of HTN. It was aimed to identify the key risk factor that triggers the conversion of normal BP into high normal values, which later on leads to progression of pre-HTN stage to HTN stage I. It was presumed to assist in early identification of susceptible individuals for preventive measures.

\section{Materials and Methods}

Study Design. Case-control study.

Sampling. Convenient.

Ethical Consideration. The study was approved by Board of Advanced Studies and Research, University of Karachi.

Subjects. The subjects $(n=276)$ were classified into four groups according to cut-off values recommended by 7 th JNC report [4] see Table 5 .

The age-matched control subjects were selected from general population with normal blood pressure readings without any medications. Pre-HTN group comprised all those subjects who were for the first time told that they have higher normal BP.

The hypertensive subjects (age 25-60 years) representing urban population (as data was collected from largest city of country) were selected amongst patients attending five general practitioners clinics. Most of the subjects were educated and belonged to middle and lower middle socioeconomic class; details are published in previous article [20].

2.1. Questionnaire. Demographic data and lifestyle behaviors was collected by purpose designed questionnaire, followed by general physical examination.

Written consent of every participant was taken.

\subsection{Anthropometric Measurements}

2.2.1. Measurement of Body Weight and Height. Subjects were weighed without shoes, in their normal clothing, using a digital scale with an accuracy of \pm 100 grams. Standing body height was measured without shoes to the nearest $0.5 \mathrm{~cm}$ by a commercial stadiometer with the shoulders in the relaxed position and arms hanging freely.

Body mass index (BMI) was calculated from standard formula $\left(\mathrm{Kg} / \mathrm{m}^{2}\right)$. The WHO recommended values for Asian population were taken as reference, $>23$ overweight and $>25$ obese [21]. 
TABLE 1: Mean values of different variables (mean \pm SD) in controls and stages of hypertension.

\begin{tabular}{|c|c|c|c|c|}
\hline Variable/group & Control $(n=75)$ & Pre-HTN $(n=55)$ & HTN stage $1(n=70)$ & HTN stage II $(n=76)$ \\
\hline Age & $37.5 \pm 8.54$ & $39.2 \pm 7.73$ & $46.2 \pm 12.1^{*}$ & $47.5 \pm 11.6^{*}$ \\
\hline Systolic BP & $106.9 \pm 10.7$ & $131.6 \pm 7.1$ & $147.3 \pm 8.4$ & $171 \pm 15.3$ \\
\hline Diastolic BP & $68.4 \pm 9.48$ & $85.9 \pm 5.8$ & $93.7 \pm 4.3$ & $105.9 \pm 9.7$ \\
\hline Body mass index & $24.9 \pm 3.77$ & $26.4 \pm 4.47$ & $28.4 \pm 4.53^{*}$ & $26.6 \pm 5.33$ \\
\hline Waist circumference & $82.2 \pm 13.4$ & $86.9 \pm 17.2$ & $97.2 \pm 11.4^{*}$ & $95.4 \pm 13.3^{*}$ \\
\hline Fasting blood glucose (FBG) & $96.6 \pm 38.4$ & $108.4 \pm 38.2^{*}$ & $103.7 \pm 32.7$ & $101 \pm 43.6$ \\
\hline Total cholesterol (TC) & $168.7 \pm 33.9$ & $171.7 \pm 32.3$ & $191.4 \pm 48.4^{*}$ & $179.1 \pm 32.1$ \\
\hline Low density lipoproteins & $106.5 \pm 30.7$ & $105.6 \pm 32.6$ & $116.4 \pm 32.4^{*}$ & $103.7 \pm 29.2$ \\
\hline Sodium $\left(\mathrm{Na}^{+}\right)$ & $141.5 \pm 3.24$ & $142.4 \pm 4.4$ & $142.2 \pm 4.3$ & $141.03 \pm 4.72$ \\
\hline Potassium $\left(\mathrm{K}^{+}\right)$ & $4.5 \pm 0.43$ & $4.47 \pm 0.42$ & $4.26 \pm 0.51$ & $4.41 \pm 0.45$ \\
\hline Aldosterone & $9.17 \pm 3.49$ & $8.76 \pm 3.31$ & $12.41 \pm 5.72$ & $12.05 \pm 6.84$ \\
\hline Cortisol & $7.61 \pm 4.15$ & $9.36 \pm 3.25$ & $9.08 \pm 3.97$ & $9.99 \pm 4.85$ \\
\hline
\end{tabular}

*The mean difference is significant at the 0.05 level, when compared among four groups.

2.2.2. Measurement of Waist Circumference (WC). It was measured in the middle between 12 th rib and iliac crest at the level of umbilicus. Normal values for males were $<83$ and for females $<79$ [22].

2.3. Blood Pressure Measurement. Subjects were seated in a chair with their back supported and their arms rested at heart level. Measurement was performed with the subject not having ingested coffee or smoked for 30 minutes and after at least five minutes of rest. The first and fifth Korotkoff sounds were recorded by the height of mercury column on sphygmomanometer. Two readings were taken and averaged.

2.3.1. Biochemical Analysis. Fasting venous blood samples were drawn (after 9-12 hours fasting), centrifuged, and analyzed (by commercially available kits) for estimation of fasting blood glucose (FBG), electrolytes $\left(\mathrm{Na}^{+}\right.$and $\left.\mathrm{K}^{+}\right)$, total cholesterol (TC), and low density lipoproteins (LDL). Serum cortisol and aldosterone were measured by ELISA.

2.4. Statistical Analysis. Data was analyzed by SPSS version 10. All variables were presented by mean \pm SD. ANOVA was performed to compare four study groups and least significance difference (LSD) test was applied to compare pair-wise groups. Test of Pearson's correlation was applied to assess relationship of hormones with variables determined and shown by Scatter plots. Coefficient determination " $r$ " was also calculated by squaring the value of $r$. It expresses the proportion of the variance in one variable that is accounted for or explained by the variance in other variable. However, it does not demonstrate a causal relationship.

\section{Results}

The subjects $(n=276)$ were almost equal with respect to sex (male: $49.6 \%$; female $50.4 \%$ ). The mean age of control group was $37.5 \pm 8.54$, pre-HTN $39.2 \pm 7.73$, HTN stage
$146.2 \pm 12.1$, and $47.5 \pm 11.6$ in stage II. Among healthy controls, $52(69.3 \%)$ were found to be overweight (BMI $>23)$ with significantly higher proportions $(P=0.023)$ of overweight individuals in pre-HTN (80\%), HTN stage I (90\%), and stage II (76.3\%) (Table 1).

The mean BMI $\left(\mathrm{kg} / \mathrm{m}^{2}\right)$ of control group $(24.9 \pm 3.77)$ was significantly less than that of pre-HTN group $(26.4 \pm 4.47)$, HTN stage I $(28.4 \pm 4.53)$, and stage II $(26.6 \pm 5.33)$ groups $(P<0.01)$. Mean WC of both HTN stage I $(97.2 \pm 11.4)$ and II $(95.4 \pm 13.3)$ was found to be significantly higher $(P<0.01)$ as compared to control $(82.2 \pm 13.4)$ and pre-HTN groups $(86.9 \pm 17.2)$ (Table 1$)$. BMI has positive correlation with cortisol in both control and pre-HTN groups and with aldosterone in control group, whereas WC have positive correlation with aldosterone in pre-HTN group only (Table 2 ).

The mean systolic BP in various groups of control, pre-HTN, and HTN were $106.9 \pm 10.7,131.6 \pm 7.1$, $147.3 \pm 8.4$, and $171 \pm 15.3$. The diastolic BP were 85.9 \pm 5.8 , $93.7 \pm 4.3$, and $105.9 \pm 9.7$ respectively, as compared to control $68.4 \pm 9.48$ (Table 1).

The mean total cholesterol (TC) level was higher in HTN stage $1(191.4 \pm 48.4)$ as compared to $168.7 \pm 33.9$ in controls $(P<0.01), 171.7 \pm 32.3$ in pre-HTN $(P<0.05)$, and $179.1 \pm 32.1$ in stage II (Table 1$)$. TC was positively correlated to aldosterone in pre-HTN group (Table 3 ). The level of LDL was higher in HTN stage $1(116.4 \pm 32.9)$ as compared to control $(106.5 \pm 30.7)$, pre-HTN $(105.6 \pm 32.7)$, and HTN stage II $(103.7 \pm 29.2)$ (Table 1$)$. LDL was positively correlated to fasting blood glucose and aldosterone in pre-HTN group (Tables 1 and 3 ).

The mean fasting blood glucose (FBG) level was in normal range in all groups but was highest in pre-HTN group $(108.4 \pm 38.2)$ as compared to controls $(96.6 \pm 38.4)$, HTN stage I $(103.7 \pm 32.7)$, and stage II $(101.0 \pm 43.6)$. FBG was correlated to LDL in pre-HTN group.

The mean aldosterone level was the highest in, HTN stage I $(12.41 \pm 5.72)$ as compared to control group $(9.17 \pm 3.49)$, pre-HTN $(8.76 \pm 3.31)$, and stage II HTN $(12.05 \pm 6.84)$. 
TABle 2: Coefficient correlation ( $r$ ) to identify the association of different variables with one another among four groups.

\begin{tabular}{|c|c|c|}
\hline Variable & Aldosterone & Cortisol \\
\hline \multicolumn{3}{|l|}{ BMI } \\
\hline Control & $0.578^{*}$ & $0.538^{*}$ \\
\hline Pre-HTN & 0.303 & $0.628^{*}$ \\
\hline HTN-I & 0.144 & 0.299 \\
\hline HTN-II & $0.544^{*}$ & 0.361 \\
\hline \multicolumn{3}{|l|}{ WC } \\
\hline Control & 0.446 & 0.352 \\
\hline Pre-HTN & $0.679 * *$ & 0.263 \\
\hline HTN-I & 0.161 & 0.149 \\
\hline HYN-II & 0.345 & 0.445 \\
\hline \multicolumn{3}{|l|}{ FBG } \\
\hline Control & 0.451 & 0.185 \\
\hline Pre-HTN & 0.483 & -0.18 \\
\hline HTN-1 & 0.362 & -0.345 \\
\hline HTN-II & -0.102 & -0.264 \\
\hline \multicolumn{3}{|l|}{ TC } \\
\hline Control & 0.041 & 0.286 \\
\hline Pre-HTN & $0.726^{* *}$ & 0.308 \\
\hline HTN-I & 0.309 & 0.043 \\
\hline HTN-II & 0.128 & 0.036 \\
\hline \multicolumn{3}{|l|}{ LDL } \\
\hline Control & 0.048 & 0.371 \\
\hline Pre-HTN & $0.620^{*}$ & 0.275 \\
\hline HTN-I & 0.161 & 0.208 \\
\hline HTN-II & 0.071 & 0.179 \\
\hline \multicolumn{3}{|l|}{$\mathrm{Na}^{+}$} \\
\hline Control & 0.108 & $0.690^{* *}$ \\
\hline Pre-HTN & 0.230 & 0.292 \\
\hline HTN-I & 0.392 & 0.200 \\
\hline HTN-II & 0.259 & 0.083 \\
\hline \multicolumn{3}{|l|}{$\mathrm{K}^{+}$} \\
\hline Control & 0.146 & $0.578^{*}$ \\
\hline Pre-HTN & 0.473 & 0.027 \\
\hline HTN-I & 0.439 & 0.151 \\
\hline HTN-II & 0.254 & 0.045 \\
\hline
\end{tabular}

* Significant at the 0.05 level.

** Significant at 0.01 level.

The serum cortisol level in four groups was $7.61 \pm 4.15$, $9.36 \pm 3.25,9.08 \pm 3.97$, and $9.99 \pm 4.85$, respectively.

Serum $\mathrm{Na}^{+}$concentration was within normal limits in all groups (control: $141.8 \pm 3.24$, pre-HTN $142.4 \pm 4.4$, stage I $142.2 \pm 4.3$, and stage II $141 \pm 4.72$ ). Serum $\mathrm{K}^{+}$level in four groups was also within normal range (Table 2 ). Both $\mathrm{Na}^{+}$and $\mathrm{K}^{+}$were positively related to cortisol in controls (Table 2 ).

The coefficient of determination $\left(r^{2}\right)$ showed that changes in BMI accounts for 39\% of variation in cortisol and $48 \%$ interdependence between sodium and cortisol, whereas dependence shared between aldosterone and cholesterol was $53 \%$ and with fasting blood glucose 23\% (Table 4).

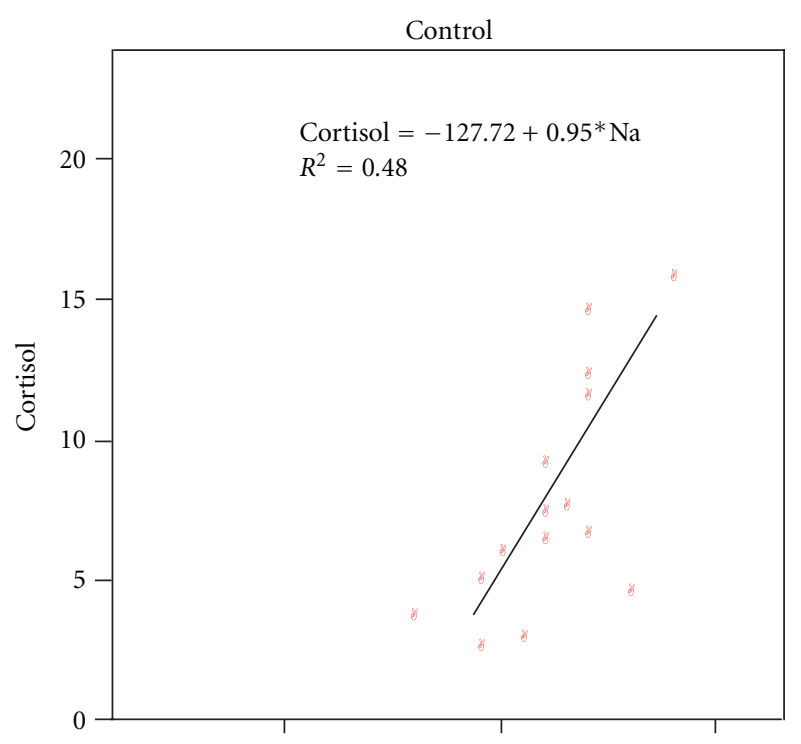

Figure 1: Correlation between sodium $\left(\mathrm{Na}^{+}\right)$and cortisol.

\section{Discussion}

This study investigated the possible interaction of aldosterone and cortisol with certain cardiovascular risk factors like obesity (BMI, WC), dyslipidemia (TC, LDL), and glycemic status of blood (FBG) in different stages of HTN. The study was focused on identification of risk factors in preHTN stage, that initiate an increase in set point BP, ultimately leading to progression of this stage into established HTN.

Rapid urbanization and migration towards cities have brought significant changes in lifestyle patterns of our population, especially excessive dietary fat and salt intake and lack of physical activity, resulting in storage of surplus fat in subcutaneous and visceral adipose tissue [23] as evidenced by higher BMI and WC of majority of subjects in our study (Table 1). According to free fatty acid (FFA) hypothesis, dietary fat is converted into triglycerides (TG), broken down into fatty acid, and taken up by fat cells where it is converted to TG again [24]. Body fat accumulation and hyperlipidemia enhance insulin resistance (IR), by increasing free fatty acid in portal blood vessels, impairing insulin signaling on one hand, and by inhibiting key signaling proteins, indicating disturbances in glucose and lipid metabolism (as revealed by significant positive correlation of LDL with FBG in this study), and lead to cortisol secretion on the other hand [25].

The enzyme hydroxysteroid dehydrogenase type-I (HDS1) converts cortisone to cortisol within insulin target tissue, such as liver, visceral adipose tissue and skeletal muscle, resulting in local GC action which by promoting adipogenesis [26] leads to IR and subsequently hyperinsulinemia; this in turn along with other adipokines results in increased aldosterone production, $\mathrm{Na}^{+}$retention, and HTN [27]. The mean cortisol levels among four study groups were within lower normal range; however, statistical analysis indicated that cortisol level was significantly correlated to BMI, $\mathrm{Na}^{+}$, and $\mathrm{K}^{+}$in controls (Figures 1 and 2) and to BMI and WC in pre-HTN group, indicating 
TABle 3: Pearson's correlation $(r)$ among important variables, showing relationship of different variables with one another in prehypertension group.

\begin{tabular}{lcccccccccc}
\hline Variables & BMI & WC & SBP & DBP & $\mathrm{Na}^{+}$ & FBG & TC & LDL & Aldost & Cortisol \\
\hline BMI & 1.00 & $.825^{* *}$ & $-.274^{*}$ & -.165 & -.126 & .207 & .078 & .201 & .303 & $.628^{*}$ \\
WC & $.825^{* *}$ & 1.00 & $-.356^{*}$ & $-.353^{*}$ & -.056 & .241 & -.058 & .103 & -.263 & $.679^{* *}$ \\
SBP & $-.274^{*}$ & -.356 & 1.00 & $.270^{*}$ & $.328^{*}$ & -.205 & -.093 & -.10 & .060 & -.38 \\
DBP & -.165 & -.353 & $.270^{*}$ & 1.00 & .059 & -.300 & .069 & .076 & .216 & -.50 \\
Na & -.126 & -.056 & $.328^{*}$ & $.059^{*}$ & 1.00 & -.267 & .034 & -.04 & .230 & .292 \\
FBG & .207 & .241 & -.205 & -.300 & -.267 & 1.00 & .205 & $.289^{*}$ & .483 & -.18 \\
TC & .078 & -.058 & -.093 & .069 & .034 & .205 & 1.00 & $.822^{* *}$ & $.726^{* *}$ & .308 \\
LDL & .201 & .103 & -.097 & .076 & -.04 & $.289^{*}$ & $.822^{* *}$ & 1.00 & $.620^{*}$ & .275 \\
Aldost & .303 & -.263 & .060 & .216 & .230 & .483 & $.726^{* *}$ & $.620^{*}$ & 1.00 & .00 \\
Cortisol & $.628^{*}$ & $.679^{* *}$ & -.380 & -.500 & .292 & -.176 & .308 & .275 & -.005 & 1.00 \\
\hline
\end{tabular}

* Significant at 0.05 level.

** Significant at 0.01 level.

SBP: systolic blood pressure, DBP: diastolic blood pressure, FBG: fasting blood glucose, TC: total cholesterol, LDL: low density lipoproteins, Aldost: aldosterone.

TABle 4: Measure of coefficient determination $\left(r^{2}\right)$ showing the proportion of variance shared among two variables in pre-HTN group.

\begin{tabular}{lcc}
\hline Variable & Cortisol & Aldosterone \\
\hline Diastolic BP & $25 \%$ & - \\
BMI & $39 \%$ & - \\
Cholesterol & - & $53 \%$ \\
LDL & - & $38 \%$ \\
Fasting blood glucose & - & $23 \%$ \\
Serum $\mathrm{Na}^{+}$ & $48 \%$ & - \\
Serum $\mathrm{K}^{+}$ & $33 \%$ & $22 \%$ \\
\hline
\end{tabular}

TABLE 5

\begin{tabular}{lcc}
\hline Stages & Systolic BP mmHg & Diastolic BP mmHg \\
\hline Control $(n=75)$ & $<120$ & $<80$ \\
Prehypertensive $(n=55)$ & $>120$ and $<140$ & $>80$ and $<90$ \\
Hypertension stage I $(70)$ & $>140$ and $<160$ & $>90$ and $<100$ \\
Hypertension stage II $(76)$ & $>160$ & $>100$ \\
\hline
\end{tabular}

its association with obesity (Table 3). The relationship between cortisol and obesity has been studied in detail; low circulating cortisol concentrations have been measured in obese individuals, which could be related to increased peripheral metabolism of cortisol [28].

The mean aldosterone level in this study was in high normal range and was found to have positive correlation with BMI and WC in controls, and to TC and LDL in preHTN group (Figures 3 and 4). Association of aldosterone with obesity, lipid levels, and IR had been confirmed by studies as adipokines and insulin stimulates aldosterone production, which in turn causes fluid retention, endothelial cell dysfunction, atherosclerosis, and HTN $[4,29]$.

A community-based study reported that even increased plasma aldosterone concentration within physiological range predisposed to the development of HTN [30]. However longterm increase reflects the interaction of unknown genetic

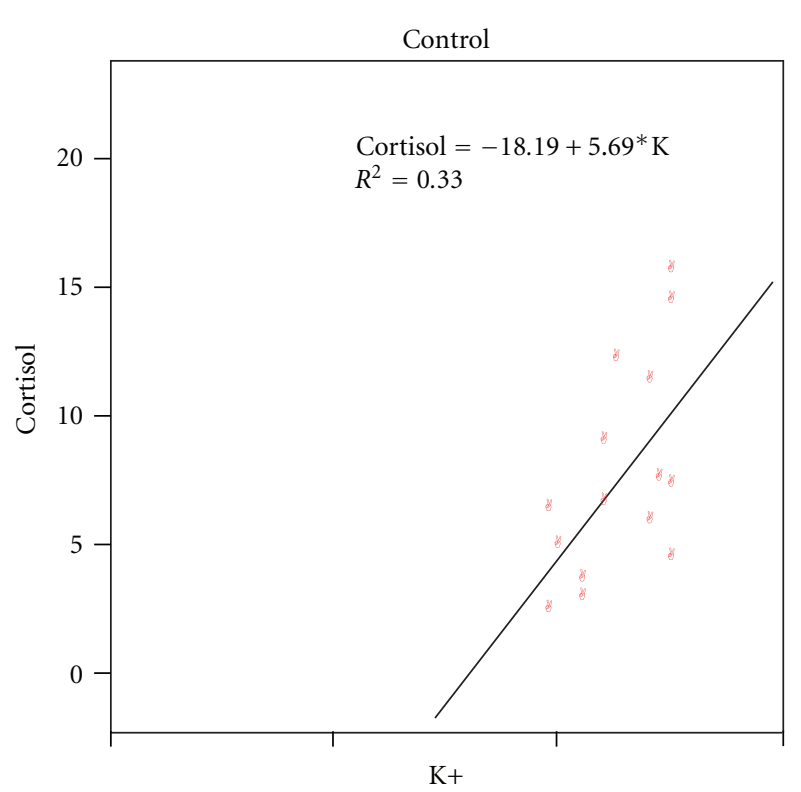

Figure 2: Correlation between potassium $\left(\mathrm{K}^{+}\right)$and cortisol.

and known environmental factors (increased dietary fat and salt intake, decreased physical activity, stress, caffeine consumption, and so forth) leading to eventual phenotype of aldosterone associated HTN and cardiovascular (CV) damage in middle age and beyond. In view of important role played by aldosterone, it is now under consideration that it should be included as the primary screening target for preventing $\mathrm{CV}$ events [31].

Plasma $\mathrm{Na}^{+}$and $\mathrm{K}^{+}$are major determinants for the mechanical stiffness of endothelial cells. High plasma $\mathrm{Na}^{+}$ levels stiffen endothelial cells and block nitric oxide (NO) synthesis (aldosterone is a prerequisite for this condition), whereas high plasma $\mathrm{K}^{+}$levels soften endothelial cells and activate NO release [32]. Clinical studies have documented that a diet low in $\mathrm{K}^{+}(10-16 \mathrm{mmol} /$ day $)$ coupled with 


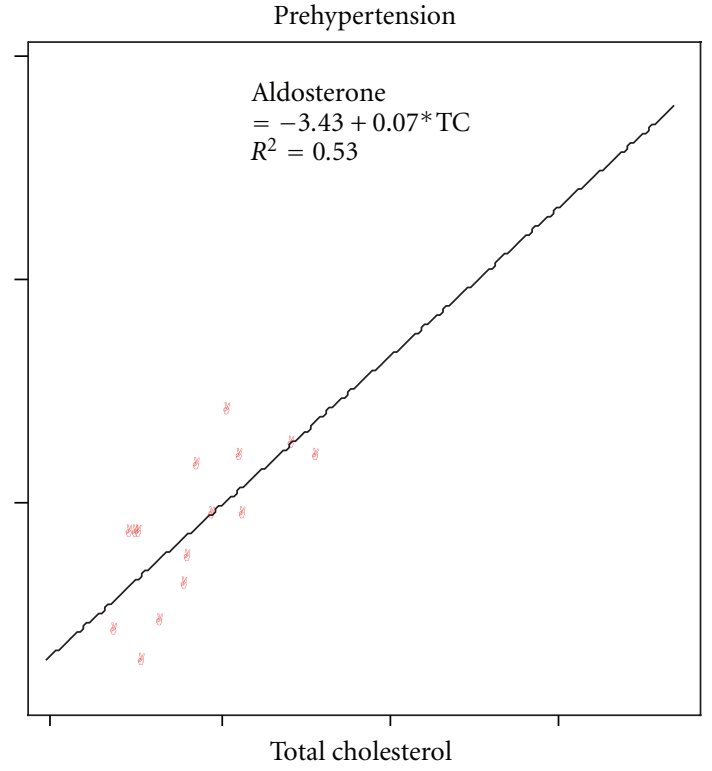

FIGURE 3: Correlation between total cholesterol and aldosterone.

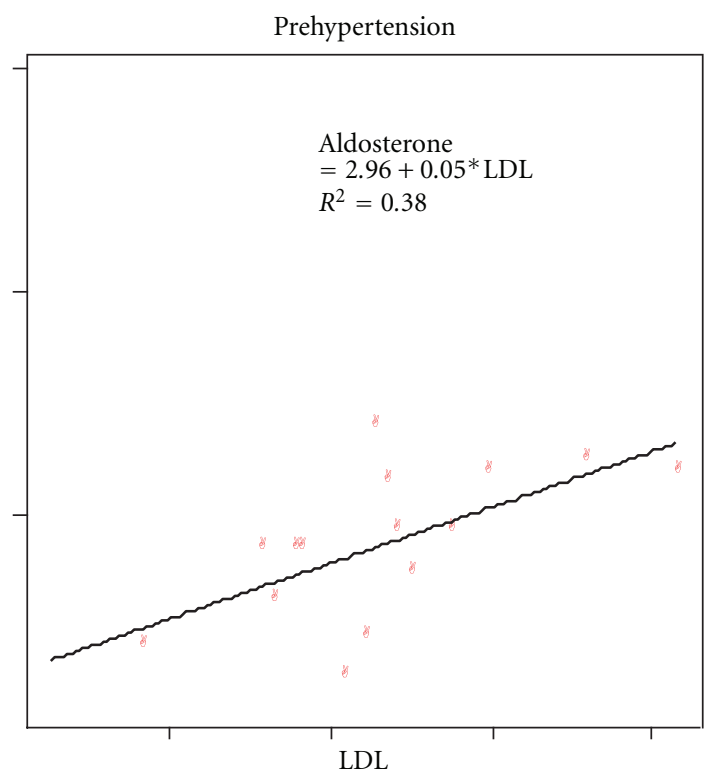

FIgURE 4: Correlation between low density lipoproteins (LDL) and aldosterone.

usual $\mathrm{Na}^{+}$intake $(120-200 \mathrm{mmol} / \mathrm{d})$ caused $\mathrm{Na}$ retention and an elevation of BP; on average systolic BP increased by $6 \mathrm{mmHg}$ and diastolic BP by $4 \mathrm{mmHg}$ in normotensive subjects and by 7 and $6 \mathrm{mmHg}$, respectively, in hypertensive subjects [33].

Data analysis in this study indicated that $\mathrm{Na}^{+}$level was normal in all four groups; however, it was positively related to BMI and cortisol in controls and to systolic and diastolic BP in pre-HTN group. The strong relationship between $\mathrm{Na}^{+}$and cortisol is very significant, as when in excess cortisol may act as an $\mathrm{MC}$, perhaps by saturating the 11-beta hydroxysteroid-dehydrogenase- 2 enzyme that inactivates cortisol at the renal tubules [28]. A study supported that abnormal $\mathrm{Na}^{+}$metabolism at the cellular level may play a role in biochemical pathway leading to HTN [34] and another study confirmed, on epidemiological grounds, the positive link of $\mathrm{Na}^{+}$and a negative link of $\mathrm{K}^{+}$to $\mathrm{BP}$ within a single population [35].

The serum $\mathrm{K}^{+}$level was within normal range and was positively related to cortisol in controls which is a significant finding, as high level of $\mathrm{K}^{+}$is considered to be a stimulus for aldosterone secretion. Cortisol and aldosterone bind to the $\mathrm{MC}$ receptor with equal affinity, but normal circulatory concentration of cortisol is 100 - to 1000 -fold higher than those of aldosterone. If 11-beta hydroxysteroid (HSD2) is oversaturated or defective, more cortisol will be available to bind MCR $[9,30]$, a condition termed as apparent MC excess (AME), characterized by low renin and aldosterone levels, normal plasma cortisol level, and hypokalemia. However because cardiomyocytes lack 11-beta HSD-2, MC receptors are normally occupied by cortisol in a tonic inhibitory fashion and their activation can be triggered by hypoxia, inflammation, and generation of reactive oxygen species causing myocardial damage [36].

Abnormal $\mathrm{K}^{+}$homeostasis is said to accompany many secondary forms as well as uncommon, inherited monogenic forms of HTN, as evidenced by $14 \%$ nonhypertensive subjects in Framingham heart study who developed HTN, when followed up to four years; however, other studies found no correlation between serum $\mathrm{K}^{+}$and HTN [37]. In IR, due to a decrease in responsiveness of cells to insulin, $\mathrm{K}^{+}$entry into the cells decreases, and its plasma level increases. The plasma $\mathrm{K}^{+}$level need to increase only $1 \mathrm{meq} / \mathrm{L}$ to stimulate aldosterone secretion.

The visceral fat accumulation in upper abdomen also activates sympathetic nervous system and renin angiotensin system. When aldosterone levels are in low- to normalrange and $\mathrm{Na}^{+}$status is unremarkable, cortisol appears to be responsible for MCR activation and aldosterone actions. Increased levels of these hormones in hypertensive subjects may be related to ACTH, which not only increases production of cortisol but also of aldosterone for short-term period [38]. Individuals with less efficient cortisol synthesis maintains a slightly enhanced ACTH drive to adrenal which in long term is likely to cause hyperplasia of both zona fasciculata and glomerulosa, resulting in increased synthetic capacity for both cortisol and aldosterone [39].

\section{Conclusion}

This study concludes the identification of pre-HTN stage among Pakistani population, with successive increase in various risk factors of HTN (obesity, dyslipidemia, hyperglycemia, and $\mathrm{Na}^{+}$), in relation to aldosterone and cortisol in different stages of HTN. This study suggests that the interaction of these risk factors with endogenous levels of aldosterone and cortisol may disrupt the set-point BP and result in increased proportion of HTN. 


\section{Recommendations}

Timely and early detection of pre-HTN stage with a few preliminary investigations is an effective method of prevention of cardiovascular disease. The physicians are recommended to actively target lifestyle patterns for multiple risk reduction in these patients, as pre-HTN stage serves as an early warning sign for both patients and clinicians that metabolic changes which ultimately lead to CVD may well be underway. Moreover, aldosterone should be included in primary screening tests for evaluation of hypertensive patients.

\section{Conflict of Interests}

There is no conflict of interests as it is a self-financed Ph.D. project of the author, not funded by any agency.

\section{References}

[1] P. M. Kearney, M. Whelton, K. Reynolds, P. Muntner, P. K. Whelton, and J. He, "Global burden of hypertension: analysis of worldwide data," The Lancet, vol. 365, no. 9455, pp. 217223, 2005.

[2] "National Health Survey of Pakistan 1990-94," Islamabad, Pakistan, Pakistan Medical Research Council, 1998.

[3] J. Pomeroy, A. M. Söderberg, and P. W. Franks, "Gene-lifestyle interactions and their consequences on human health," Medicine and Sport Science, vol. 54, pp. 110-135, 2009.

[4] A. V. Chobanian, G. L. Bakris, H. R. Black et al., "The seventh report of the joint national committee on prevention, detection, evaluation, and treatment of high blood pressure: the JNC 7 report," Journal of the American Medical Association, vol. 289, no. 19, pp. 2560-2572, 2003.

[5] M. Caprio, B. G. Newfell, A. La Sala et al., "Functional mineralocorticoid receptors in human vascular endothelial cells regulate intercellular adhesion molecule-1 expression and promote leukocyte adhesion," Circulation Research, vol. 102, no. 11, pp. 1359-1367, 2008.

[6] I. Z. Jaffe and M. E. Mendelsohn, "Angiotensin II and aldosterone regulate gene transcription via functional mineralocortocoid receptors in human coronary artery smooth muscle cells," Circulation Research, vol. 96, no. 6, pp. 643-650, 2005.

[7] J. C. Buckingham, "Glucocorticoids: exemplars of multitasking," British Journal of Pharmacology, vol. 147, no. 1, pp. S258-S268, 2006.

[8] J. R. Seckl, "11 $\beta$-hydroxysteroid dehydrogenases: changing glucocorticoid action," Current Opinion in Pharmacology, vol. 4, no. 6, pp. 597-602, 2004.

[9] J. Fagart, J. Huyet, G. M. Pinon, M. Rochel, C. Mayer, and M. E. Rafestin-Oblin, "Crystal structure of a mutant mineralocorticoid receptor responsible for hypertension," Nature Structural and Molecular Biology, vol. 12, no. 6, pp. 554-555, 2005.

[10] J. D. Horisberger, "Amiloride-sensitive Na channels," Current Opinion in Cell Biology, vol. 10, no. 4, pp. 443-449, 1998.

[11] P. J. Fuller and M. J. Young, "Mechanisms of mineralocorticoid action," Hypertension, vol. 46, no. 6, pp. 1227-1235, 2005.

[12] D. S. Geller, A. Farhi, N. Pinkerton et al., "Activating mineralocorticoid receptor mutation in hypertension exacerbated by pregnancy," Science, vol. 289, no. 5476, pp. 119-123, 2000.
[13] M. Stowasser, F. Fallo, A. So et al., "Genetic forms of primary aldosteronism," High Blood Pressure \& Cardiovascular Prevention, vol. 14, no. 2, pp. 75-81, 2007.

[14] T. L. Goodfriend, D. L. Ball, B. M. Egan, W. B. Campbell, and K. Nithipatikom, "Epoxy-keto derivative of linoleic acid stimulates aldosterone secretion," Hypertension, vol. 43, no. 2 , pp. 358-363, 2004.

[15] J. R. Sowers, A. Whaley-Connell, and M. Epstein, "Narrative review: the emerging clinical implications of the role of aldosterone in the metabolic syndrome and resistant hypertension," Annals of Internal Medicine, vol. 150, no. 11, pp. 776-783, 2009.

[16] J. T. Ho, J. B. Keogh, S. R. Bornstein et al., "Moderate weight loss reduces renin and aldosterone but does not influence basal or stimulated pituitary-adrenal axis function," Hormone and Metabolic Research, vol. 39, no. 9, pp. 694-699, 2007.

[17] C. B. Whorwood, S. J. Donovan, D. Flanagan et al., "Increased glucocorticoid receptor expression in human skeletal muscle cells may contribute to the pathogenesis of the metabolic syndrome," Diabetes, vol. 51, no. 4, pp. 1066-1075, 2002.

[18] J. A. Whitworth, P. M. Williamson, G. Mangos, and J. J. Kelly, "Cardiovascular consequences of cortisol excess," Vascular Health and Risk Management, vol. 1, no. 4, pp. 291-299, 2005.

[19] T. H. Jafar, "Blood pressure, diabetes, and increased dietary salt associated with stroke-results from a community-based study in Pakistan," Journal of Human Hypertension, vol. 20, no. 1, pp. 83-85, 2006.

[20] S. Syed, M. R. Hingorjo, A. Charania, and M. A. Qureshi, "Anthropometric and metabolic indicators in hypertensive patients," Journal of the College of Physicians and Surgeons Pakistan, vol. 19, no. 7, pp. 421-427, 2009.

[21] WHO. World Health Organization, "Appropriate body mass index for Asian population and its implications for policy and intervention strategies," The Lancet, vol. 363, no. 9403, pp. 157-163, 2004.

[22] NCEP National Cholesterol Education Program, 2002.

[23] T. Kelly, W. Yang, C. S. Chen, K. Reynolds, and J. He, "Global burden of obesity in 2005 and projections to 2030," International Journal of Obesity, vol. 32, no. 9, pp. 1431-1437, 2008.

[24] T. G. Coatmellac and C. Ribierc, "Factors that influence the risk of hypertension in obese individuals," Current Opinion in Nephrology \& Hypertension, vol. 12, no. 3, pp. 305-308, 2003.

[25] B. M. Egan, "Insulin resistance and the sympathetic nervous system," Current Hypertension Reports, vol. 5, no. 3, pp. 247254, 2003.

[26] J. W. Tomlinson, E. A. Walker, I. J. Bujalska et al., " $11 \beta$ hydroxysteroid dehydrogenase type 1: a tissue-specific regulator of glucocorticoid response," Endocrine Reviews, vol. 25, no. 5, pp. 831-866, 2004.

[27] S. Kidambi, J. M. Kotchen, C. E. Grim et al., "Association of adrenal steroids with hypertension and the metabolic syndrome in blacks," Hypertension, vol. 49, no. 3, pp. 704-711, 2007.

[28] T. M. Stulnig and W. Waldhäusl, " $11 \beta$-hydroxysteroid dehydrogenase type 1 in obesity and type 2 diabetes," Diabetologia, vol. 47, no. 1, pp. 1-11, 2004.

[29] V. Lamounier-Zepter and M. Ehrhart-Bornstein, "Fat tissue metabolism and adrenal steroid secretion," Current Hypertension Reports, vol. 8, no. 1, pp. 30-34, 2006.

[30] C. A. Koch, M. R. Wofford, A. R. Ayala et al., "Overview of endocrine hypertension," 2006, http://www.endotext.org/ adrenal/adrenal26/adrenal26.htm. 
[31] G. S. Francis and W. H. W. Tang, "Should we consider aldosterone as the primary screening target for preventing cardiovascular events?" Journal of the American College of Cardiology, vol. 45, no. 8, pp. 1249-1250, 2005.

[32] E. Büssemaker, U. Hillebrand, M. Hausberg, H. Pavenstädt, and H. Oberleithner, "Pathogenesis of hypertension: interactions among sodium, potassium, and aldosterone," American Journal of Kidney Diseases, vol. 55, no. 6, pp. 1111-1120, 2010.

[33] H. J. Adrogue and N. E. Madias, "Sodium and potassium in the pathogenesis of hypertension," The New England Journal of Medicine, vol. 356, no. 19, pp. 1966-1978, 2007.

[34] J. C. Verhave, H. L. Hillege, J. G. M. Burgerhof et al., "Sodium intake affects urinary albumin excretion especially in overweight subjects," Journal of Internal Medicine, vol. 256, no. 4, pp. 324-330, 2004.

[35] J. M. Geleijnse, J. C. M. Witteman, T. Stijnen, M. W. Kloos, A. Hofman, and D. E. Grobbee, "Sodium and potassium intake and risk of cardiovascular events and all-cause mortality: the Rotterdam Study," European Journal of Epidemiology, vol. 22, no. 11, pp. 763-770, 2007.

[36] J. W. Funder, "Mineralocorticoid receptors: distribution and activation," Heart Failure Reviews, vol. 10, no. 1, pp. 15-22, 2005.

[37] C. R. Walsh, M. G. Larson, R. S. Vasan, and D. Levy, "Serum potassium is not associated with blood pressure tracking in the Framingham heart study," American Journal of Hypertension, vol. 15, no. 2, part 1, pp. 130-136, 2002.

[38] E. Davies, C. D. Holloway, M. C. Ingram et al., "An influence of variation in the aldosterone synthase gene (CYP11B2) on corticosteroid responses to ACTH in normal human subjects," Clinical Endocrinology, vol. 54, no. 6, pp. 813-817, 2001.

[39] J. M. C. Connell and E. Davies, "The new biology of aldosterone," Journal of Endocrinology, vol. 186, no. 1, pp. 120, 2005. 


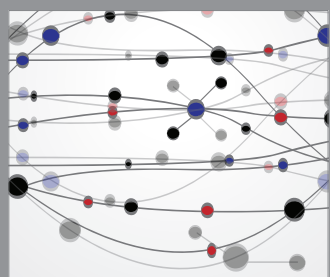

The Scientific World Journal
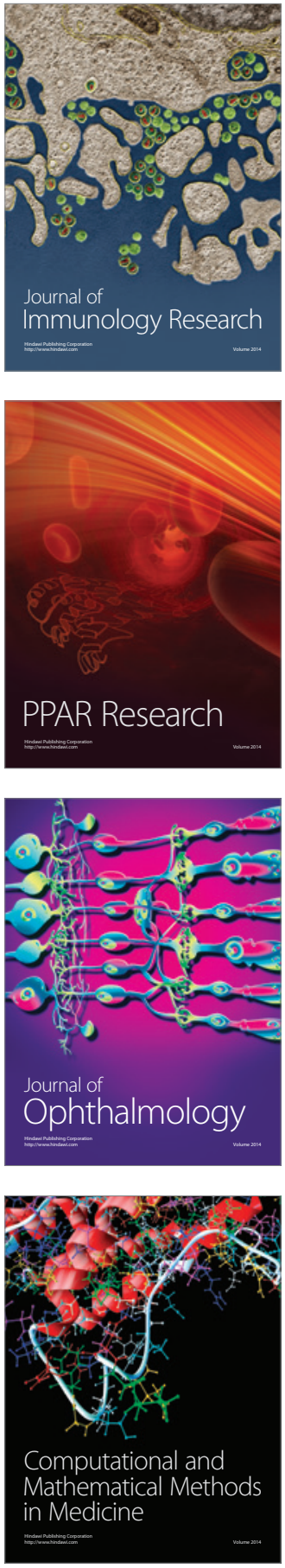

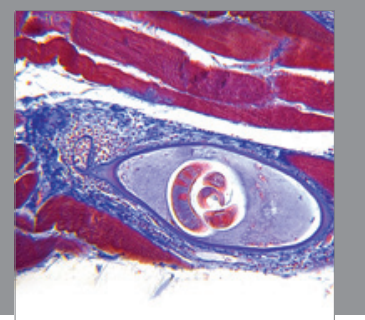

Gastroenterology

Research and Practice
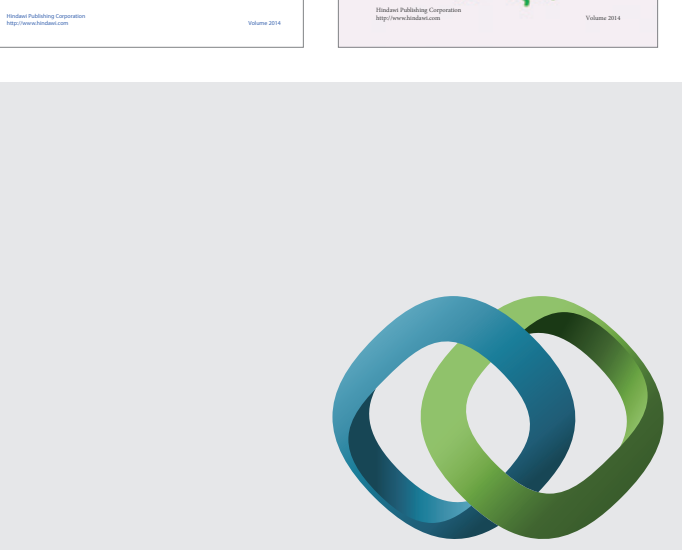

\section{Hindawi}

Submit your manuscripts at

http://www.hindawi.com
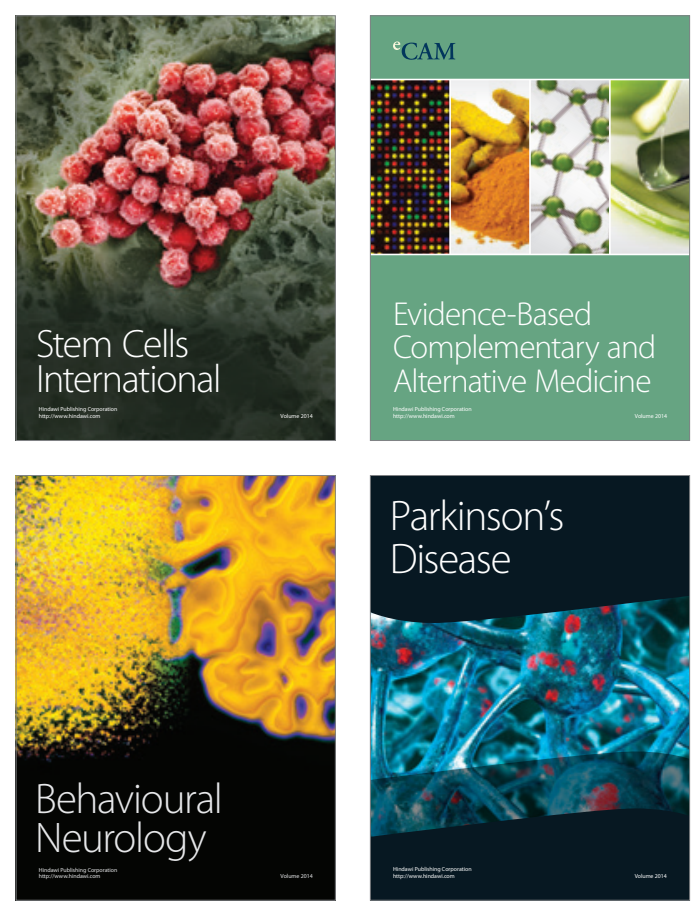

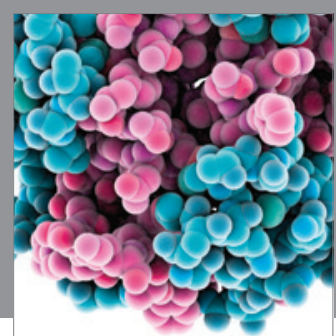

Journal of
Diabetes Research

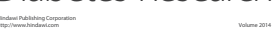

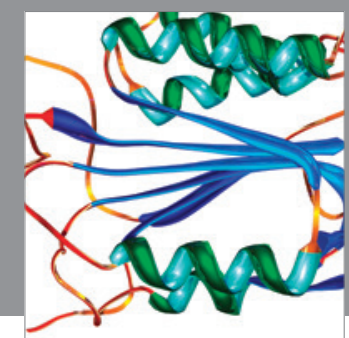

Disease Markers
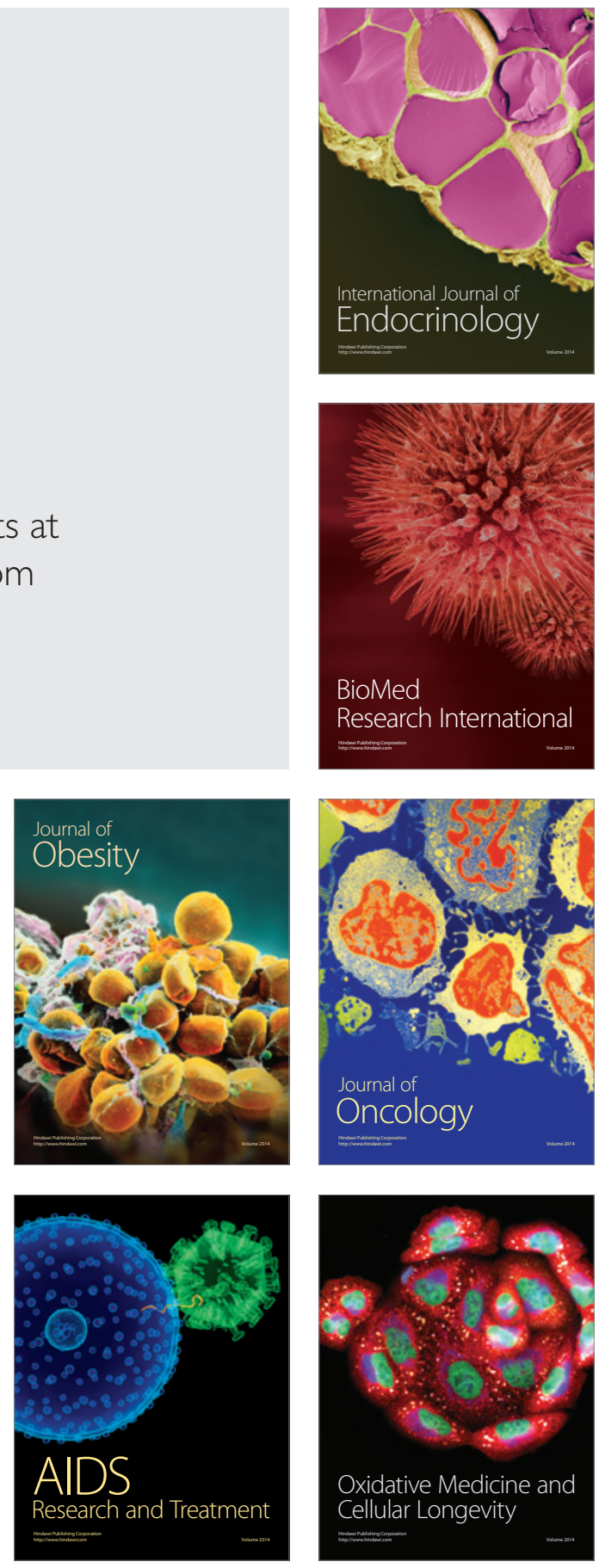